\title{
Does the Use of Case-based Learning Impact the Retention of Key Concepts in Undergraduate Biochemistry?
}

\author{
Verena Kulak ${ }^{1}$, Dr. Genevieve Newton ${ }^{2} \&$ Rahul Sharma ${ }^{3}$ \\ ${ }^{1}$ MSc., Research Assistant, Human Health and Nutrition, University of Guelph, Canada \\ ${ }^{2}$ Associate Professor, Human Health and Nutrition, University of Guelph, Canada \\ ${ }^{3}$ MSc., Human Health and Nutrition, University of Guelph, Canada \\ Correspondence: Genevieve Newton, Associate Professor, Human Health and Nutrition, University of Guelph, \\ Canada \\ Received: February 15, 2017 \\ Accepted: March 21, 2017 \\ Online Published: March 30, 2017 \\ doi:10.5430/ijhe.v6n2p110 \\ URL: https://doi.org/10.5430/ijhe.v6n2p110
}

\begin{abstract}
Objective: Enhanced knowledge retention and a preference towards a deep learning approach are desirable pedagogical outcomes of case-based learning (CBL). The CBL literature is sparse with respect to these outcomes, and this is especially so in the area of biochemistry. The present study determined the effect of CBL vs. non CBL on knowledge retention in an undergraduate biochemistry course; it also investigated associations of learning approach, age and gender.

Methods: We used the Revised Two-Factor Study Process Questionnaire, a retention test, final exam grades and other demographic information to statistically compare academic outcomes of students subjected to either CBL or non-CBL active learning techniques.

Results: We showed that students exposed to CBL in a second year course performed significantly better on a retention test conducted nine months after the final exam, and that there was a positive correlation between a deep learning approach and higher retention scores. We did not find an association between gender and age with the retention of biochemistry concepts.
\end{abstract}

Conclusions: Our findings suggest that use of CBL in undergraduate biochemistry education may confer benefits in terms of retention of knowledge of key concepts.

Keywords: Case-based learning, Retention, Biochemistry, Learning approach, Age, Gender

\section{Introduction}

Case based learning (CBL) is a tool used to enhance learning through the use of case studies that are presented to students for them to solve (Davis, 2004). CBL is an umbrella term that includes many types, which have variable suitability for different academic environments (Kulak \& Newton, 2014). Available evidence indicates that CBL offers several pedagogical benefits to students, including improvements in: a) students' intrinsic motivation to learning (Facione, 2000; Ferrari \& Mahalingam, 1998;), b) sophistication of critical thinking skills (Ennis, Millman \& Tomko, 2005), c) retention of knowledge (Malau-Aduli, Lee, Cooling, Catchpole, Jose \& Turner, 2013) , d) encouragement of self-evaluation and reflection (Cliff \& Wright, 1996), and e) effective collaboration interactions (Wenger, 1998; Webb \& Palincsar, 1996). CBL has been widely used in education, with observed variation in outcomes related to academic discipline (Herreid, 2012; Gijbels, Dochy, Van den Bossche \& Segers, 2005; Grady, Gouldsborough, Sheader \& Speake, 2009), student age and gender (Malau et al., 2013; Das Carlo, Swadi \& Mpofu, 2003; Mpofu, Das, Stewart, Dunn \& Schmidt, 1998) and student approach to learning (Das Carlo et al., 2003; Mpofu et al., 1998). Student approaches to learning were originally defined by Marton and Säljö (1976) as deep (high level of student engagement with the material) or surface (rote learning, little engagement with material), the present study follows these definitions.

The refinement of critical thinking skills and intrinsic motivation are generally accepted outcomes of CBL. These outcomes are associated with meaningful learning, a process that includes several cognitive phases, such as the acquisition of new information, the anchoring of new ideas, and interaction between new meanings and relevant ideas in the learners mind. It has been suggested that cognitive processes associated with meaningful learning also mediate knowledge retention (Ausubel, 2012). Therefore, it seems fitting to assess if and how these outcomes connect to knowledge retention in a CBL environment. In cognitive psychology, it is generally accepted that students must use mental strategies in order to remember new material (Gagne, 1985). Students must elaborate or think about 
the material and construct a link between it and other information already held in memory. Retention of knowledge involves the maintenance of knowledge, after acquisition, over a specified period of time and refers to students' ability to remember what they were taught (Semb, Ellis \& Araujo, 1993; Fisher, Williams \& Roth, 1981; Anderson, 2007). Knowledge retention has received less research attention than some other benefits of CBL, likely due to difficulties in conducting longitudinal educational studies. However, available evidence suggests that student characteristics may be associated with the retention of knowledge within a CBL environment. Student characteristics are independent and external factors that are difficult for the researcher to manipulate, such as approach to learning, age and gender (Ansari, Jaiwal \& Goshwamin, 2015; Khan \& Sobani, 2012). For example, Das Carlo, Swadi and Mpofu (2003), showed that female student groups exhibited greater elaboration strategies in CBL sessions that male groups. Also, Mpofu and colleagues (1998) showed that females groups prioritized their learning objectives on exam success and overall learning, whereas in male groups, group participation was the most imperative objective. Additionally, gender by age group interactions were shown to be significant in Malau-Aduli et al. (2013), whereby younger male students outperformed older male students and older female students outperformed younger female student in the biochemistry, and anatomy sections and overall scores of a retention exam. So, the association between student characteristics and knowledge retention in a CBL environment warrants further investigation.

In general terms, retention studies focusing on introductory biochemistry education within the undergraduate or medical school curricula have commonly demonstrated a knowledge decline as the students' progress through their programs and that the magnitude of the decline is worse for biochemistry than for other disciplines when taught under traditional pedagogical conditions (Ling, Swanson, Holtzman \& Bucak, 2008). Studies that focus on CBL's effect on biochemistry content retention are lacking. One of the few examples is presented in Malau-Aduli et al. (2013), whom did not observe a benefit of CBL on retention. However, their study lacked a control group and the students were exposed to a CBL curriculum including various types of CBL. Given the pedagogical benefits of CBL previously discussed, it is worth investigating its effect on retention further by carefully designing the experimental conditions and avoiding confounders.

\subsection{Overview of Case-Based Learning}

The use of real-life case scenarios in teaching makes learning more applicable and relevant to students, and when CBL involves group work, it can enhance communication skills (Fernandez-Santander, 2008; Savery, 2006). In addition, CBL is a student-involved process encouraging students to take accountability for their learning - and in doing so students develop the critical thinking and transferable skills including life-long learning needed outside of academia (Hartfield, 2010). Taken as a whole, CBL is an evidence-based instructional method shown to enable students to problem solve via gathering and applying pertinent information, retaining relevant knowledge and improving communication skills (Biggs \& Tang, 2011).

There are several types of CBL, such as: lecture-based, interrupted, jigsaw, PBL (problem-based learning) and the directed-case method (Kulak \& Newton, 2014). In general terms, the types of CBL vary in terms of the nature of material provided, the method of presentation of case material, the amount of direction provided, and the level of need for expert facilitation. For example, while the lecture-based type allows a case and its solutions to be described as part of a traditional lecture, the directed-case method allows students to work actively in a group, with the provision of several closed-ended case questions. In contrast, the PBL approach provides more complex cases without directed questions, and is highly self-directed. Similar to the directed case method, the jigsaw method breaks students into groups, although each group deals only with a single question; a subsequent phase of group work then ensues in which new groups are formed that are comprised of "experts" on each of the questions. Lastly, the interrupted method provides progressive disclosure of pertinent case information to students, again working in groups, with instructor facilitation of the case solution. Each CBL type has suitability for different educational contexts; a detailed review is provided in Kulak and Newton (2014).

In CBL, students are expected to solve elaborate questions that can be open ended and require articulate explanations to problems (Kulak \& Newton, 2014). Elaboration, as a cognitive strategy, has been associated with retention of knowledge (Gagne, 1985). Semb, Ellis and Araujo (1993) compared long-term content retention among students who were taught using a conventional lecturing method vs. an active learning method. The authors showed that the performance on the retention exam related to "recognition" and "recall" questions decreased as a function of time in both groups, but retention rates were still higher for the recognition questions particularly among the students in the active learning group. Likewise, Fisher and colleagues (1981) demonstrated that students exposed to active learning performed better on the "meaningful" rather than "rote" questions on retention exams, than students taught using only lectures. Furthermore, CBL has shown promise across a number of content-rich science disciplines with respect to knowledge retention (Malau-Aduli et al., 2013), so a focus of ongoing work is to better elucidate how this pedagogy benefits learning in undergraduate biochemistry courses. 
In summary, CBL is an instructional technique that is both student-centred and based on group work, and can benefit students in several ways, but there is a gap in the literature with respect to knowledge retention in the teaching of biochemistry. Similarly, approach to learning, gender and age are some student characteristics that have been shown to be associated with knowledge retention in numerous academic disciplines. However, the evidence related to how these characteristics influence the learning of biochemistry is again, rare. As such, the primary research question in the present study was to determine whether the use of CBL in undergraduate biochemistry education would improve the retention of key concepts. The secondary question was to ascertain whether the retention of course material was associated with students' characteristics such as age, gender and preferred approach to learning. To that effect, we hypothesized that CBL will improve the retention of key concepts in biochemistry, and that knowledge retention may be associated with student characteristics.

\section{Methods}

\subsection{Subjects}

Subjects in this study were students enrolled in a kinesiology program that leads to a Bachelor of Applied Science degree at the University of Guelph Humber. The classes at this University are relatively small in size in comparison to most Canadian Universities. Subjects were enrolled in four separate offerings of a second year introductory biochemistry course (Fall 2012, n=64 students; Winter 2013, n=42 students; Fall 2013, n=63 students; and Winter 2014, $n=41$ students), all of which were taught by the same instructor. Each course ran for twelve weeks, with content presented in modules that described human metabolism. The Fall 2012 and Winter 2013 classes comprised the non-CBL control group, while the Fall 2013 and Winter 2014 classes comprised the CBL intervention group. All students in each course were invited to participate in the study, with respondents giving informed consent and completing the retention test as follows: Fall 2012 (non-CBL) $n=16$; Winter 2013 (non-CBL) n=20; Fall 2013 (CBL) $\mathrm{n}=27$; and Winter 2014 (CBL) $\mathrm{n}=10$. Statistical comparison of the final course grades of participating students in each class revealed no significant differences, with a mean final course grade of $79.13+/-1.15$ percent. Data was considered for each class independently as well as combined into a single non-CBL $(n=36)$ and CBL $(n=37)$ group. The pooled analyses for the non-CBL condition included the Fall 2011 and Winter 2012 classes, while the CBL condition included the Fall 2012 and Winter 2013 classes, here we are reporting the pooled results, as we did not find significant differences across groups exposed to the same conditions.

\subsection{Case-Based Learning}

In the present study, the directed type of CBL was used. Directed CBL is quite structured, and allows for lectures or other pedagogies to be combined with the case study. The cases are accompanied by a set of questions with close-ended answers and supporting material (here, figures, tables, and text) to guide students into specific topics. This CBL type allows the instructor to set time limits and to monitor the construction of information to prevent students from diverging from the main topic, thus it is a suitable technique to teach content heavy courses such as biochemistry (Cliff \& Wright, 1996). The cases used in this study were designed following the protocol delineated in Kulak \& Newton (2014). As illustrated in figure 1, each module in the course involved four tasks, including orientation to the case study, a lecture, peer instruction, and large class case review. Between the case orientation and the peer instruction, students had time to find answers to the directed questions. Each group was comprised of five to seven students, and each student was assigned one to two questions to answer, with up to seven questions per case. An example of a case vignette used in the study is shown in figure 2.

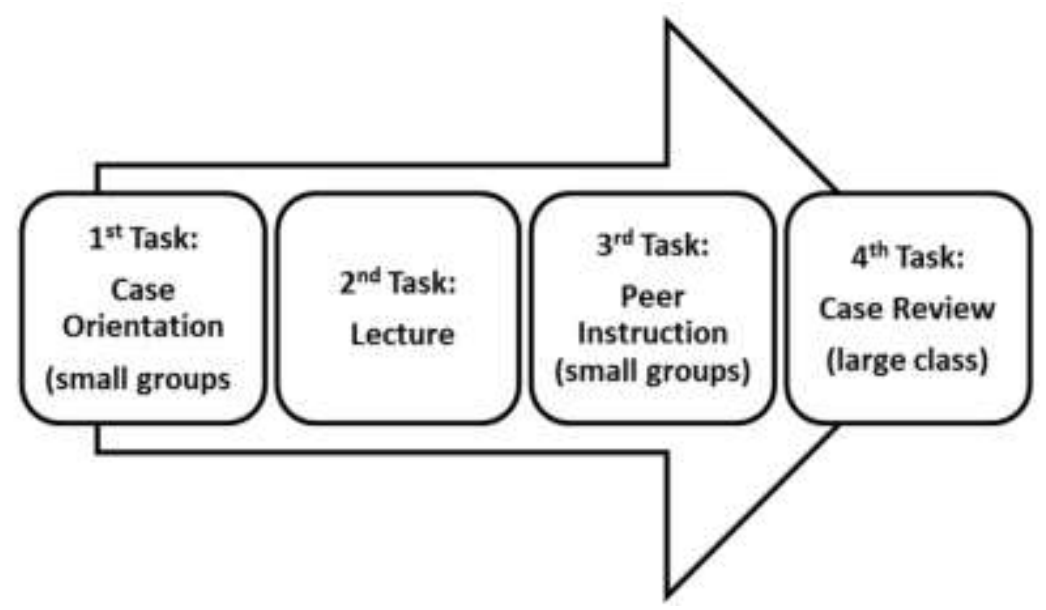

Figure 1. CBL process used for each module 


\section{Scenario:}

Avery's Bad Day

Avery, a 22-year-old fitness trainer and body builder was preparing for an upcoming competition. With four weeks left before competition she was unhappy with her current muscle definition. While reading a fitness forum online, Avery came across the herbal supplement BulkFX, a popular fat burner manufactured in Asia. Avery mail ordered a thirty-day supply of BulkFX providing $500 \mathrm{mg}$ of usnic acid, $25 \mathrm{mg}$ of caffeine and 25 $\mathrm{mg}$ inulin per day. She incorporated BulkFX into a self-designed diet of high protein, some complex carbs, low fat and plenty of water. Her initial weight $(127 \mathrm{lb})$ and height $\left(5^{\prime} 0\right)$ yielded a healthy BMI of 24.8 . Within ten days into her regimen, Avery developed flu-like symptoms (fever, myalgias and vomiting). At day thirteen, she was so fatigued that she was unable to exercise; she was jaundiced, had light-clay-coloured stools and felt mildly confused. Her fiancé took her to the ER and after blood and liver tests, several abnormalities were noted (see table a), also her liver ATP levels were below normal. Avery had no previous liver issues. Illicit drug, virulent, bacterial, auto-immune and pregnancy tests came back negative. She later became comatose and was put on a liver transplant waiting list due to fulminant liver failure. After a successful transplant, Avery regained full consciousness and her blood serum and liver tests were back to normal; she never took BulkFX again.

\begin{tabular}{|l|l|l|}
\hline Table a: Blood serum and liver test results & Avery's & Normal values \\
\hline Fasting Blood Glucose $(\mathrm{mMol} / \mathrm{L})$ & 7 & 6.1 \\
\hline Pyruvate $(\mu \mathrm{Mol} / \mathrm{L})$ & 28 & 25 \\
\hline $\mathrm{NAD}+(\mu \mathrm{Mol} / \mathrm{L})$ & 6 & 75 \\
\hline $\mathrm{NADH}(\mu \mathrm{Mol} / \mathrm{L})$ & 383 & 50 \\
\hline $\mathrm{H}_{2} \mathrm{O}_{2}$ (from breath test) & 0.48 & 0.24 \\
\hline
\end{tabular}

Learning issues:

1) Avery's liver histology revealed extensive mitochondrial damage with ATP levels very reduced, however acetyl Co A levels were normal. Also serum ALT and AST levels were higher than normal ( $1636 \mathrm{U} / \mathrm{L}$ and $1536 \mathrm{U} / \mathrm{L}$ respectively) and her bilirubin level was $23.0 \mathrm{mg} / \mathrm{dL}$. What cellular processes were impaired in Avery's liver?

2) For each metabolite listed in table 2, describe its role in cellular respiration. Are they substrates or products? What is their main function?

3) Which component on Avery's weight loss regime was the most likely suspect to have caused liver failure within the disclosed time frame? Explain in detail the mechanism of action by which this component is known to affect biochemical processes,

4) Some health food stores sell NAD+ and NADH supplements, if Avery had taken them as part of her regime, could her liver have been saved, or symptoms delayed? Why or why not? What role does NAD+ play in metabolism in general, and specifically, in the process affected in this case?

5) Had Avery been put on a breathing oxygen pump on arrival at the ER, would her condition have improved? What is the role of oxygen in metabolism, and what happens under anaerobic conditions in general and in this process specifically?

6) Avery's twin brother, Derek was also a body builder (BMI 27,5'8). He decided to take BulkFX as well. Derek took the same daily dose as Avery did but he kept a normal diet and figured he could have better results by taking an endurance drink containing antioxidants such as vitamin $\mathrm{C}$ and $\mathrm{E}$. Derek did not develop many symptoms beyond fatigue and lower ATP levels. He had normal bilirubin levels but had elevated serum ALT (1462 U/L) and AST (451 U/L). After stopping the supplementation his liver began to improve. Aside from gender differences and BMI that could result in changes in bioactive/drug metabolism, what can be attributed to the contrast in health status for these siblings?

Figure 2. Example case used in the study

In the non-CBL control group, students were exposed to the same lectures as the CBL group. Instead of tasks one, three, and four described in figure 1, students participated in a variety of general active learning activities that involved application, analysis, and synthesis such as generation of concept maps. These activities were similarly done in small groups. No activities were associated with cases. The time dedicated to small group active learning activities in the non-CBL group was approximately equal to the CBL group, for further details on implementation of these activities in our research see Kulak and Newton (2015). 


\subsection{Student Approach to Learning}

Student approach to learning was measured using the Revised Two-Factor Study Process Questionnaire (R-SPQ-2F). Biggs, Kember and Leung (2001) suggest that the R-SPQ-2F is a useful tool to assess teaching innovations and evaluate teaching and learning in the classroom, which was a specific aim of the present study. This questionnaire is designed to measure whether students take a deep or surface approach to learning. It is a revised version of the original Study Process Questionnaire (SPQ) designed by Biggs (1987). The R-SPQ-2F is a statistically validated tool that consists of 20 questions (Biggs et al., 2001), and our investigation followed the factor analysis performed by Justicia, Pichardo, Cano, Berbén and De La Fuente (2008). The R-SPQ-2F scores were measured at the end of the semester after completion of the final exam. All students in the class were invited to complete a web-based R-SPQ-2F via email.

\subsection{Additional Demographic Data}

Student gender and age were collected in the web-based survey administered at the end of the semester.

\subsection{Retention Test}

The retention test was administered approximately nine months after students completed the course. All students in the class were invited to complete a web-based test of ten short answer questions that addressed key concepts across all modules in the course. The retention test questions are presented in Table 1. Each question was worth two marks, for a total of 20 possible marks. Two individuals (the course instructor and a graduate student researcher) scored each test independently and in a blinded fashion.

Table 1. Retention test questions covering key concept in the biochemistry course.

\begin{tabular}{l}
\hline Questions \\
\hline 1. What is cellular respiration? \\
2. What is metabolism? \\
3. What metabolic pathways are active when someone is eating? \\
4. Why do we need to maintain blood glucose at all times? \\
5. How is $\mathrm{CO}_{2}$ related to metabolism? \\
6. Why can't we use fatty acids to make glucose? \\
7. What are the hormones that regulate metabolism? \\
8. What molecules do we find in our body that can be used for energy? \\
9. What is a redox reaction? \\
10. How does the movement of electrons generate energy in the electron transport chain?
\end{tabular}

\subsection{Statistical Methods}

Version 24 of the Statistical Package for the Social Sciences (SPSS) software was used in this study. Normality of data was assessed using the Kolmogorov-Smirnov test. Independent samples T-tests were conducted to compare retention test scores in each pooled condition. Linear regression analyses were conducted to compare retention test scores by the type of learning approach. Linear regressions were broken down by learning approach - deep approach (DA) and surface approach (SA). Two linear regressions were conducted per each learning approach (DA, SA) in each treatment condition: i) CBL condition, ii) non-CBL condition. Similar to above, two linear regression analyses were conducted for age in each treatment condition. A final linear regression was conducted to compare retention test scores by treatment condition and DA score. A two-way ANOVA (analysis of variance) was conducted to compare retention test scores as a function of treatment condition and gender (significance was set at $p<0.05$ ).

\section{Results}

The CBL group $(\mathrm{M}=12.65, \mathrm{SE}=0.79)$ performed significantly better on the retention test than the non-CBL group $(\mathrm{M}=10.59, \mathrm{SE}=0.54 ; \mathrm{p}=0.007)$ as measured by independent sample t-tests in each pooled condition. When retention test scores were analyzed as a function of treatment condition and gender, gender was non-significant ( $\mathrm{p}=0.856$ ). There were no interaction effects of teaching treatment and gender on retention scores. Refer to figure 3 for a graphic representation of these results. 


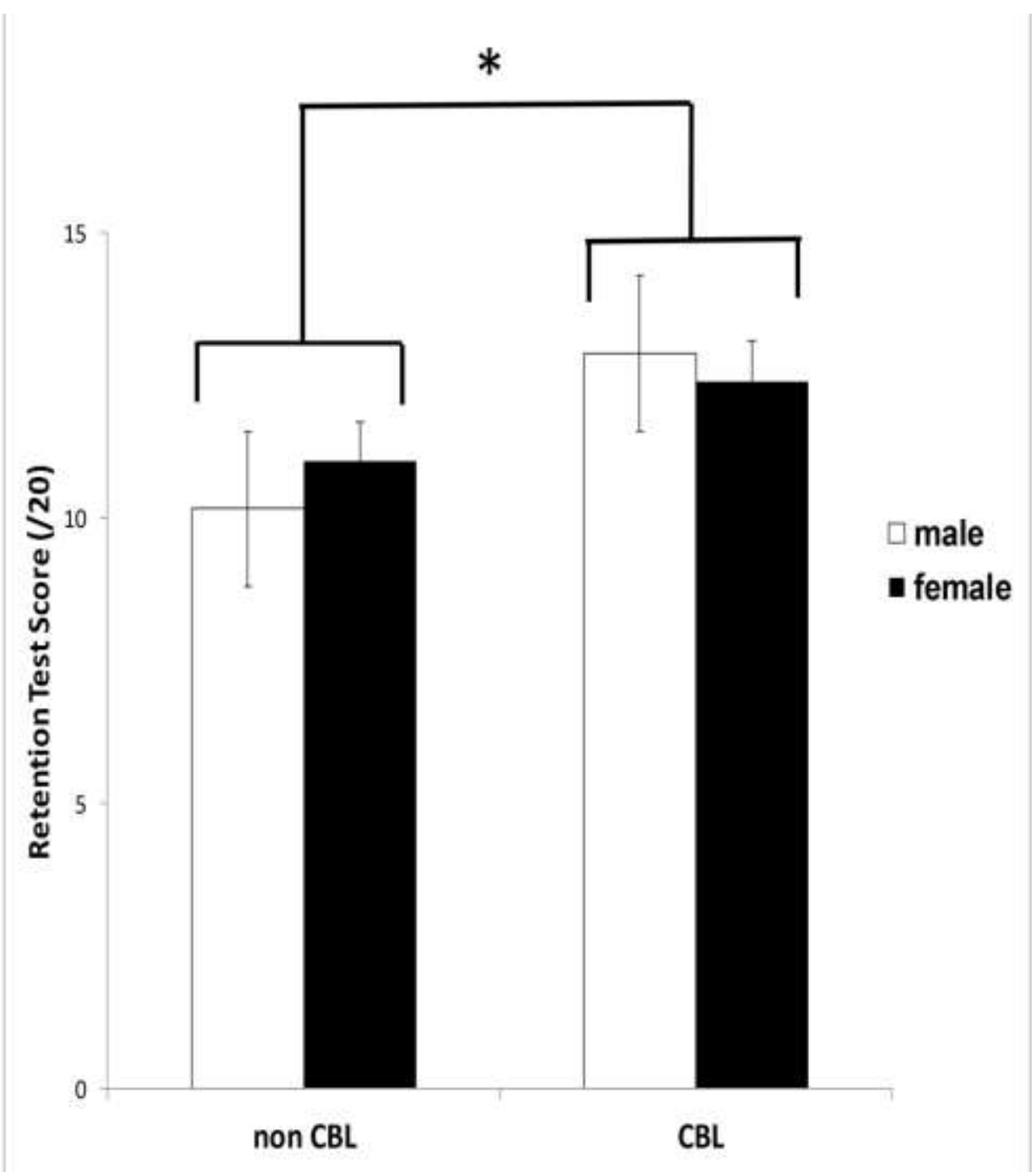

Figure 3. Teaching condition and retention scores relationship significance for non-CBL and CBL pooled groups. Star symbolises significance $\mathrm{p}=0.005$

Deep approach score significantly predicted retention test scores in the CBL condition, and there was a moderate positive correlation $\left(r=0.324, p \leq 0.005, \mathrm{R}^{2}=0.105\right.$, figure $\left.4 \mathrm{~A}\right)$. Deep approach score did not significantly predict retention scores in the non-CBL condition $\left(r=0.036, p \leq 0.005, R^{2}=0.001\right.$, figure $\left.4 B\right)$. Note that figures $4 A$ and $4 B$ display less data points that total $\mathrm{n}$ due to some identical values obtained for more than one student. Surface approach scores did not predict retention test scores in any of the conditions; all findings were non-significant. There were no significant associations between retention test scores and age. 


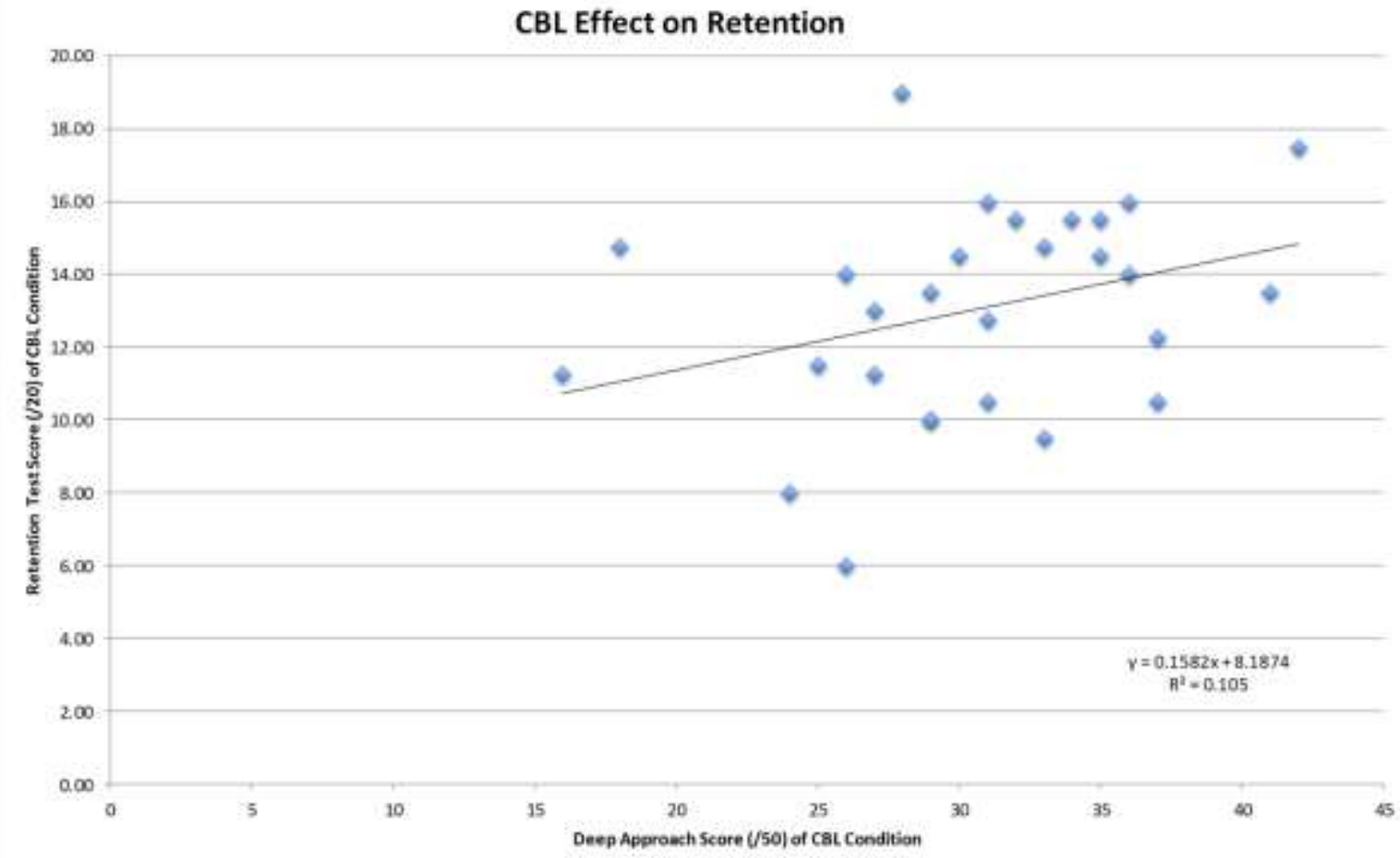

Figure 4A. Correlation between deep approach to learning and retention scores for the pooled CBL group

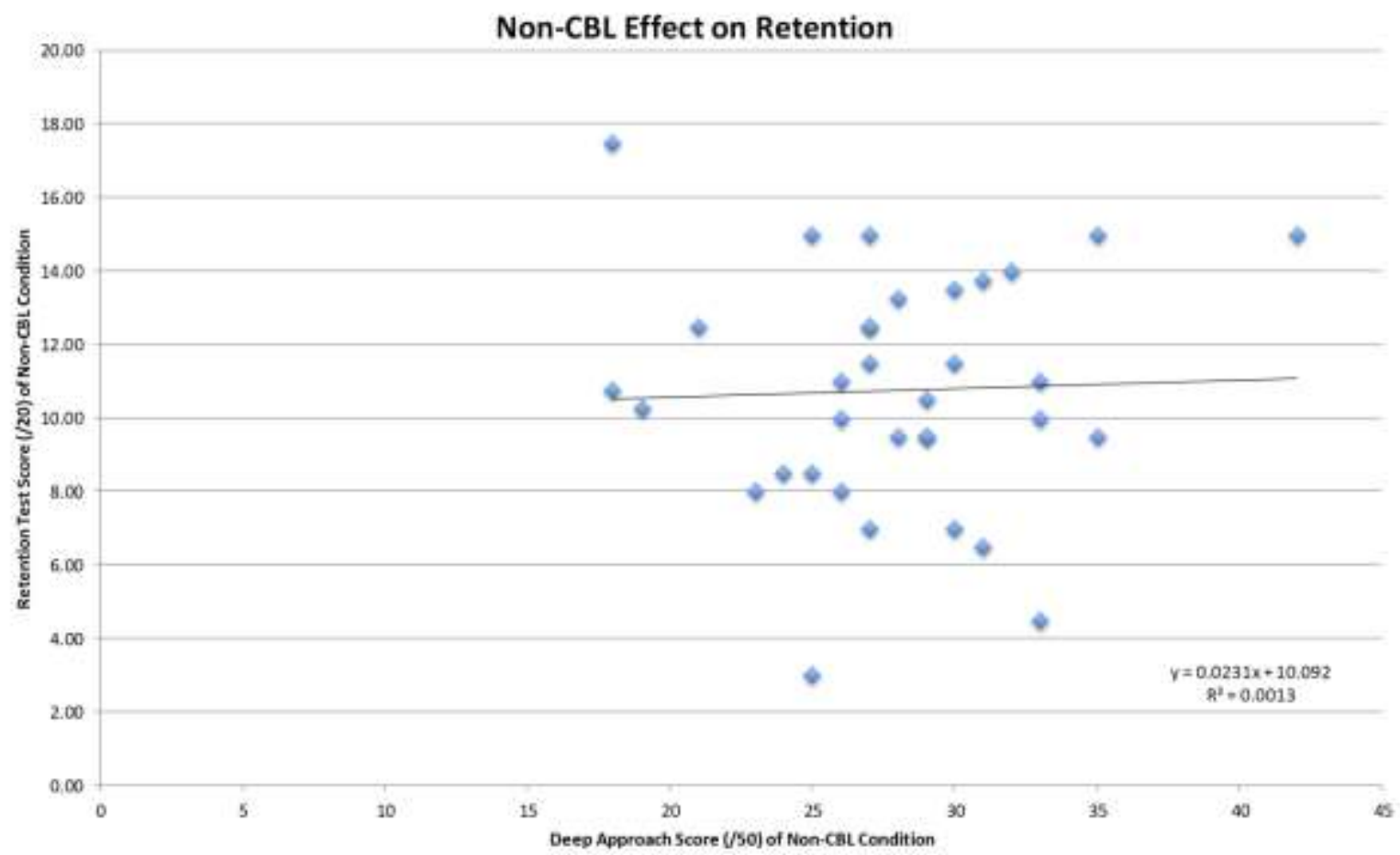

Figure 4B. Correlation between deep approach to learning and retention scores for the pooled non CBL group 


\section{Discussion}

To reiterate, the primary research question of the present study was to determine whether the use of CBL in an undergraduate biochemistry course would improve the retention of key concepts. There were statistically significant improvements in the retention scores of the CBL class compared to the non-CBL class, and the DA score significantly predicted retention scores in the CBL condition, although this resulted in a moderate correlation. There were non-significant associations of DA score on retention scores in the non-CBL class, SA score on retention scores in either of the conditions, and age on retention scores in either condition. Similarly, there was no effect of gender on retention scores in either condition.

The present study demonstrated a significant difference in the retention test scores of CBL students compared to the non-CBL students, such that students in the CBL class scored better than their non-CBL counterparts. This finding is similar to the El-Shaer \& Gaber (2014) study, wherein nursing students in the experimental PBL class exhibited a non-significant trend towards higher mean knowledge retention scores than the control or non-PBL class on a retention test given three months following completion of the course. It is therefore notable that the present study found a significant difference in retention scores nine months after course completion, as knowledge decays across time. We hypothesize that the reduced requirement of self-direction accompanying our use of CBL, and the clear directions given to students, may have enhanced retention in comparison to the self-directed nature of the PBL used by El-Shaer \& Gaber (2014). The retention test in the present study was not face to face but web based. This method may facilitate students to use books or other material to respond to the questions. However, the risk of using other sources would have been the same for all groups and should not bias the results towards the CBL group specifically. Students in the non-CBL group scored just over 50\%, while students in the CBL group scored over $60 \%$ on that test on average.

In contrast to our findings and the non-significant improvement of El-Shaer \& Gaber (2014), Malau-Aduli et al. (2013) did not observe a benefit of CBL on retention in their cohort study of medical students. Specifically, in their cohorts of second through fifth year medical students taught using a CBL curriculum, the second year students performed significantly worse on the biochemistry portion of the retention exam than upper year students. The authors suggested that the lack of clinical experience and the high content density of junior years were main contributors for the poor performance. The findings of their study, however, should be interpreted with caution as it lacked a control group, while our study did. Furthermore, there was no delay between the course/year completion and the retention exam. Students were given the retention exam two months prior to final exams (Malau-Aduli et al., 2013). Given these factors, the degree of comparability of those previous studies to the present study is severely hindered. This suggests the need for more studies with comparable experimental conditions.

Although retention scores were significantly improved with the use of CBL, this effect was not related to student gender in our study. Evidence gauging the relationship between gender and retention of knowledge is very sparse, particularly when considering the retention of biochemistry knowledge within a CBL framework. Nonetheless, there is a small amount of relevant literature. For example, Kassab, Abu-Hijleh, Al-Shboul and Hamdy (2005) revealed that female PBL groups exhibited significantly higher group performance with respect to information sharing and listening in comparison to the male PBL groups $(\mathrm{p}<0.01)$. Based on this gender evidence it is possible that this factor may contribute to better knowledge retention in an academic course offering using a CBL framework. Overall, while our study revealed no effect of gender, other studies using PBL and CBL have demonstrated gender differences in group work (Das Carlo et al., 2003; Kassab et al., 2005). This suggests a requirement for more research to closely examine the variable association(s) of gender with knowledge retention.

In our study, deep approach predicted retention score in the CBL condition. However, in the non-CBL condition, there was no clear association of DA with retention score. Currently, we are unaware of any previous literature correlating learning approach with knowledge retention. However, some literature has examined the relationship between CBL and approach to learning. In a previous study (Kulak \& Newton, 2015), we found that biochemistry students in a non-CBL class progressively opted for a surface approach from the beginning to the end of the course, while a CBL class did not exhibit this trend and performed significantly higher in the final exam $(\mathrm{p}<0.001)$. We suggested that the CBL environment prevented a shift towards a surface approach by providing meaningful experiences that facilitated problem-solving, and knowledge co-construction. This information was corroborated by focus groups interviews, where students described in detail that CBL promoted their motivation to learn and to understand the material by exposure to real-life case scenarios, for further details on how focus groups were used, see Kulak \& Newton (2015). In Bevan, Chan \& Tanner (2014), students in a CBL biochemistry course exhibited significantly higher deep learning both at the beginning and end of their semester course, compared to students in a 
parallel running non-CBL course ( $p>0.001$ ). Specifically, students in the non-CBL course exhibited a rapid shift in learning approach such that their surface learning increased substantially at the end of the semester, thus mitigating any significant differences in favour of a deep approach at the end of the course and semester. In the CBL group, a significant difference was maintained between deep approach and surface approach both at the beginning and end of the course (deep approach decreased slightly at course end and surface approach increased slightly). Tiwari and colleagues (Tiwari et al., 2006) found that students exposed to PBL significantly improved their deep approach to learning from beginning to completion of a clinical education course. Although this study did not focus on biochemistry teaching nor include a control group, it included data from focus groups interviews that provide further insight into the student experience. Altogether, these observations provide empirical support to further investigations on the relationships between CBL and learning approach. Therefore, while previous literature has demonstrated that CBL is associated with a shift from surface to deep learning approach, the present study is the first to specifically demonstrate an association between CBL, learning approach, and retention of knowledge.

In the present study, while deep approach predicted retention in the CBL class, the association of age with retention was non-significant in all conditions. Also, it did not show any association for age. This may be because the age range was not large enough between all of the classes, as the study only considered students in a second year undergraduate course.

\subsection{Strengths and Limitations}

This study has several strengths and weaknesses that should be considered. A major strength relates to use of the directed type of CBL, which requires minimal facilitation at the small group level and is therefore relatively easy to implement in the classroom. In the present study, there was only one facilitator interacting with the entire class. The facilitator did not have special training in the use of CBL beyond the guidelines provided in Kulak and Newton (2014). This allowed all students to be exposed to the same style of orientation and same level of teaching expertise, which avoided confounders in the study. The purpose of the facilitator in the directed method is simply to guide students through the four tasks, as seen in figure 1. This straight-forward strategy may prevent cognitive confusion related to goals and objectives which in turn may motivate students to persist in solving the cases. Another strength relates to the use of carefully designed case studies that provided both breadth and depth of content associated with each of the course modules. The cases used in the study were created by the course instructor along with graduate students trained in the area of biochemistry, following an extensive literature review of how to use and develop case studies in science and beyond. Involvement of graduate students in this process was helpful as they were able to utilize their prior experiences to suggest topics that would be relatable and interesting to students at the undergraduate level. The study design included the use of four separate classes, two which were exposed to CBL and two which were not (non-CBL). Since the classes at Guelph Humber are relatively small, the study design purposely used four independent groups over a two-year period. The use of four groups was considered an advantage relative to many other educational research studies that include fewer groups. Using various groups served to generate robust data for each condition. Also, the non-CBL groups served as quasi-controls which strengthened the results: the CBL condition was compared to a non-CBL condition that included some active learning rather than strictly traditional lecturing; this served to avoid confounding results due to effects of active learning per se versus traditional lecturing. The students in all four groups undertook two R-SPQ- $2 \mathrm{~F}$ tests, one at the beginning of the course and one at the end. This allowed for data collection to determine if changes in their approach to learning were associated to CBL exposure and not merely to active learning in general (Kulak \& Newton, 2015).

Limitations of the study included a small $\mathrm{n}$ and a lack of randomization. Also, there was the narrow spread of age between all of the classes. However, this was unavoidable given that only a single course was involved. Nonetheless, with regard to statistical analysis and power, it is important to note that statistical power is a function of both sample size and effect size. When the effect size is large, smaller samples can be used to detect significant differences. The present study detected a significant difference in knowledge retention between the two groups and based on statistical foundations it seems to suggest a relatively large effect size. The study focused on the second-year undergraduate biochemistry offering as part of the kinesiology program, so the results reflect effects of CBL on this particular course and discipline.

\section{Conclusion}

This study considered whether the use of case studies in undergraduate biochemistry education would improve the retention of key concepts across time, and whether there were associations between retention and student characteristics including LA, gender, and age. A significant effect of CBL on knowledge retention was observed, as evidenced by improved scores on the retention test of key concepts administered nine months after completion of the 
course. Furthermore, it was observed that deep learning approach predicted retention score in the CBL condition but not in the non-CBL condition. Differences with respect to surface approach, gender and age were non-significant. These results are highly relevant given the broad benefits of CBL, including facilitating critical thinking and problem solving, increasing student motivation, and fostering collaboration in the classroom, as well as the relative ease with which the direct method of CBL used in the present study can be applied. Taken together, these positive findings substantiate the need for more research in the areas of CBL and knowledge retention, including measuring outcomes with students across a range of ages, beyond a single course, and with longer term follow up.

\section{References}

Davis M. (2004). The successful use of case studies in nutritional biochemistry. Georgia J Sci, 62, 79-86.

Kulak V, Newton G. (2014). A guide to using case-based learning in biochemistry education. Biochem Molec Biol Educ, 42, 457-473. doi: 10.1002/bmb.20823

Facione P. (2000). The Disposition toward critical thinking: Its character, measurement, and relationship to critical-thinking skill. Informal Logic, 20, 61-84. http://dx.doi.org/10.22329/il.v20i1.2254

Ferrari M, Mahalingam R. (1998). Personal cognitive development and its implications for teaching and learning. Educ Psych, 33, 35-44. https://doi.org/10.1207/s15326985ep3301_3

Ennis RH, Millman J, Tomko TN. (2005). The Cornell Critical Thinking Tests, Level X and Z, $5^{\text {th }}$ ed. revised. Midwest Publications: Pacific Grove.

Malau-Aduli BS, Lee AYS, Cooling N, Catchpole M, Jose M, Turner R. (2013). Retention of knowledge and perceived relevance of basic sciences in an integrated case-based learning (CBL) curriculum. BMC Med Educ, 13, 139-148. https://doi.org/10.1186/1472-6920-13-139

Cliff W, Wright A. (1996). Directed case study method for teaching human anatomy and physiology. Adv Physiol Educ, 15, S19-S28.

Wenger E. (1998). Communities of Practice: learning, meaning and identity. Cambridge University Press: Cambridge. https://doi.org/10.1017/CBO9780511803932

Webb NM, Palincsar AS. (1996). Group processes in the classroom. In D. C. Berliner, \& R.C. Calfee (Eds.), Handbook of educational psychology. Macmillan: New York, 841-873.

Herreid CF. The future of case teaching in science. National Science Foundation. Retrieved from http://www.ccce.divched.org/sites/www.ccce.divched.org/files/p1_herreid.pdf

Gijbels D, Dochy F, Van den Bossche P, Segers M. (2005). Effects of problem-based learning: A meta-analysis from the angle of assessment. Rev Educ Res, 65, 27-61. https://doi.org/10.3102/00346543075001027

Grady R, Gouldsborough I, Sheader E, Speake T. (2009). Using innovative group-work activities to enhance the problem-based learning experience for dental students. Eur J Dent Educ, 13, 190-198. https://doi.org/10.1111/j.1600-0579.2009.00572.x

Das Carlo M, Swadi H, Mpofu D. (2003). Medical Student Perceptions of Factors Affecting Productivity of Problem-Based Learning Tutorial Groups: Does Culture Influence the Outcome? Teach Learn Med, 15, 59-64. https://doi.org/10.1207/S15328015TLM1501_11

Mpofu DJS, Das M, Stewart T, Dunn E, Schmidt H. (1998). Perceptions of group dynamics in problem-based learning sessions: a time to reflect on group issues. Med Teach, 20, 421-7. https://doi.org/10.1080/01421599880508

Marton F, Säljö R. (1976). On qualitative differences in learning - I: outcome and process. British J Educ Psychol, 46, 115-127. https://doi.org/10.1111/j.2044-8279.1976.tb02304.x

Ausubel DP. (2012). The acquisition and retention of knowledge: A cognitive view. Springer Science \& Business Media: Houten.

Gagne ED. (1985). The cognitive psychology of school learning. Little, Brown and Company: Boston.

Semb GB, Ellis JA, Araujo J. (1993). Long-term retention of knowledge learned in school. J Educ Psych, 85, 305-316. https://doi.org/10.1037/0022-0663.85.2.305

Fisher, KM, Williams S, Roth J. (1981). Qualitative and quantitative differences in learning associated with frequent multiple choice testing. J Res Sci Teach, 18, 449-464. https://doi.org/10.1002/tea.3660180508 
Anderson JC. (2007). Effect of problem based learning on knowledge acquisition, knowledge retention and critical thinking ability of agricultural students in urban schools. Ph.D. Thesis. University of Missouri: Missouri.

Ansari M, Jaiwal S, Goshwamin D. (2015). Comparative survey on retention of clinical pharmacology knowledge among students who have completed the second year at a medical college of Central Nepal. American J Health Res, 3, 1-5.

Khan MAA, Sobani Z. (2012). Influence of gender and ethnicity on Problem based learning. J Pak Med Stud, 2, 120-121.

Ling Y, Swanso, DB, Holtzman K, Bucak, SD. (2008). Retention of basic science information by senior medical students. Acad Med, 83, S82-S85. https://doi.org/10.1097/ACM.0b013e318183e2fc

Fernandez-Santander A. (2008). Cooperative learning combined with short periods of lecturing. Biochem. Mol Biol Educ, 36, 34-38. https://doi.org/10.1002/bmb.20141

Savery JR (2006). Overview of problem-based learning: Definitions and distinctions. Interdiscip J Probl Learn, 1, 9-20. https://doi.org/10.7771/1541-5015.1002

Hartfield P. (2010). Reinforcing constructivist teaching in advanced level Biochemistry through the introduction of case-based learning activities. J Learn Des, 3, 20-31. https://doi.org/10.5204/jld.v3i3.59

Biggs JB, Tang C. (2011). Teaching for Quality Learning At University, 4th ed. The Society for Research into Higher Education \& Open University Press:Berkshire.

Biggs JB, Kember D, Leung DYP. (2001). The Revised Two Factor Study Process Questionnaire: R-SPQ-2F. Brit J Educ Psychol, 71, 133-149. https://doi.org/10.1348/000709901158433

Biggs J. (1987). Student approaches to learning and studying. Australian Council for Educational Research: Melbourne.

Justicia F, Pichardo MC, Cano F, Berbén ABG, De La Fuente J. (2008). The revised two-factor study process questionnaire (R-SPQ-2F): exploratory and confirmatory factor analyses at item level. Eur J Psychol Educ, 23, 355-372. https://doi.org/10.1007/BF03173004

El-Shaer A, Gaber H. (2014). Impact of problem-based learning on students' critical thinking dispositions, knowledge acquisition and retention. J Educ Prac, 5, 74-83.

Kassab S, Abu-Hijleh M, Al-Shboul Q, Hamdy H. (2005). Gender-related differences in learning in student-led PBL tutorials. Educ Health, 18, 272-282. https://doi.org/10.1080/13576280500148577

Kulak V, Newton G. (2015). An investigation of the pedagogical impact of using case-based learning in a undergraduate biochemistry course. Int J Higher Educ, 4, 13-24.

Bevan SJ, Chan CW, Tanner JA. (2014). Diverse assessment and active student engagement sustain deep learning: A comparative study of outcomes in two parallel introductory biochemistry courses. Biochem Molec Biol Educ, 42, 474-479. https://doi.org/10.1002/bmb.20824

Tiwari A, Chan S, Wong E, Wong D, Chui C, Wong A, Patil N. (2006). The effect of problem-based learning on students' approaches to learning in the context of clinical nursing education. Nurse Educ Today, 26, 430-438. https://doi.org/10.1016/j.nedt.2005.12.001 